\title{
The Significance of Disintegration Testing in Pharmaceutical Development
}

\author{
Daniela Amaral Silva ${ }^{1}$, Gregory K Webster ${ }^{2}$, Nadia Bou-Chacra ${ }^{3}$, and Raimar Löbenberg ${ }^{1, *}$ \\ ${ }^{1}$ Faculty of Pharmacy and Pharmaceutical Sciences, Katz Group-Rexall Centre for Pharmacy and Health Research, \\ University of Alberta, Edmonton, $A B$, Canada \\ ${ }^{2}$ Global Research and Development, AbbVie Inc., North Chicago, IL, USA \\ ${ }^{3}$ Faculty of Pharmaceutical Sciences, University of Sao Paulo, Sao Paulo, SP, Brazil \\ e-mail: raimar@ualberta.ca
}

\section{ABSTRACT}

Disintegration is a physical process related to the mechanical breakdown of a tablet or granulate particle into smaller particles. This review investigates disintegration mechanisms, pharmacopeial use of the disintegration test and scientific studies showing its utility and potential as a pharmaceutical performance test. With a proper dosage form understanding and demonstration/justification of the mechanistic details of drug dissolution from a dosage form, dissolution testing might be replaced by disintegration testing as a performance test. However, more research is needed to make disintegration test results more mechanistically valuable in pharmaceutical development. This might lead to a reliable performance test and potentially an in-vivo predictive disintegration test in the future.

KEYWORDS: Disintegration, dissolution, QbD, drug development

\section{INTRODUCTION}

D isintegration is a physical process related to the mechanical breakdown of a tablet into smaller particles/granules, representing the breakage of inter-particle interactions generated during tablet compaction of granulated particles of the active pharmaceutical ingredient (API) and excipients (1). Generally speaking, after the liquid wets the tablet surface and penetrates the pores, disintegration takes place in two steps: first, tablet disintegration into small granules, and second, disaggregation or granule disintegration (2). The first step is important for the rate of initial drug release from the tablet. Gelling of a disintegrant, however, slows this process down. If no disintegration would occur, only the API near the surface of the compact would dissolve. The increase in surface area compared to the intact tablet yields a higher dissolution rate. In the second step, an even faster drug dissolution rate is achieved due to the increased surface area in contact with the medium, as represented in the scheme shown in Figure 1 (3).

Disintegrants can be added to the formulation to promote the dosage form (DF) disintegration when in contact with a fluid (4). Such excipients soften the DF matrix, allowing disintegration by different mechanisms $(1,4-7)$. The different mechanisms of tablet disintegration are summarized in Table 1.

In immediate release (IR) systems, drug release from the DF begins with the liquid wetting the solid and subsequent

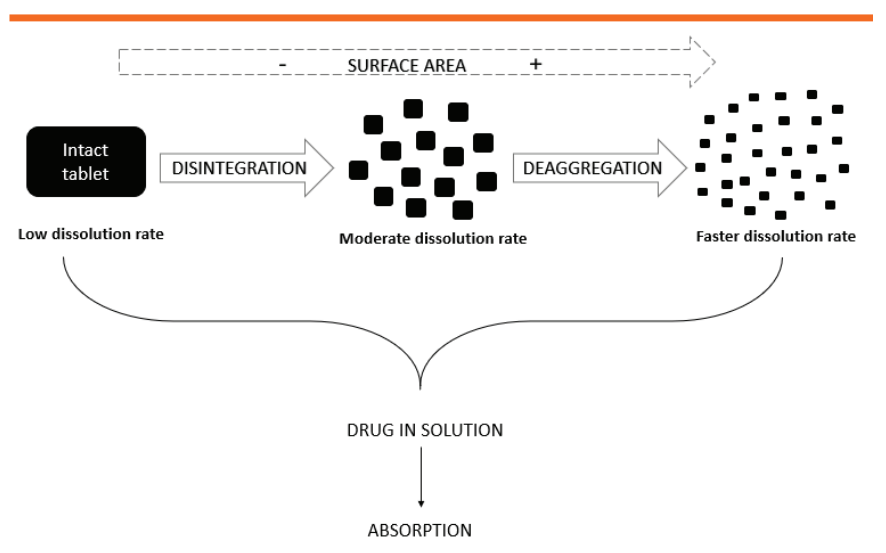

Figure 1. Immediate release tablet disintegration process.

disintegration; thus, this step is of primary importance and a prerequisite for dissolution followed by absorption and bioavailability of the API (1). Although it cannot measure the amount of drug released, disintegration is, for IR tablets, the first process before dissolution can occur.

The disintegration test basically consists of placing a DF in an immersion medium under defined experimental conditions and measuring the time taken for the DF to disintegrate (8). The time in which the tablet or capsule should disintegrate is defined in the applicable monograph. The United States Pharmacopoeia (USP) defines complete disintegration as the "state in which any residue of the unit, except fragments of insoluble coating or capsule shell, remaining on the screen of the test apparatus or adhering to the lower surface of the

* Corresponding author. 


\begin{tabular}{|c|c|c|}
\hline MECHANISM & DESCRIPTION & References \\
\hline \multirow[t]{3}{*}{$\begin{array}{l}\text { WICKING } \\
\text { (CAPILLARY } \\
\text { ACTION) }\end{array}$} & $\begin{array}{l}\text { - The liquid enters the DF compact through the pores by capillary action. Subsequently the interparticulate bonds } \\
\text { generated during tablet compression, such as intermolecular forces, solid bridges, and mechanical interlocking that } \\
\text { hold the solid particles together to maintain the structural integrity of the DF are disrupted. Thus, wicking (liquid } \\
\text { penetration) is one of the main steps in the disintegration of a DF. }\end{array}$ & \multirow[t]{3}{*}{$(1,4-7,36)$} \\
\hline & $\begin{array}{l}\text { - How much the liquid penetrates in the DF is closely related to the micro-pore structure (pore size) of the compact } \\
\text { and also the hydrophilicity of excipients added in the compact, not just the disintegrants. }\end{array}$ & \\
\hline & $\begin{array}{l}\text { - The balance between capillary force and viscous forces also plays a role in disintegration. Viscous forces act in } \\
\text { the opposite way of capillary forces. As the liquid goes into the DF, the viscous forces increase, decreasing the } \\
\text { total penetration rate. Nevertheless, simultaneously to this, a breakage of the matrix can occur, increasing the } \\
\text { penetration rate. }\end{array}$ & \\
\hline \multirow[t]{4}{*}{ SWELLING } & One of the most accepted mechanisms in disintegration. & \multirow[t]{4}{*}{$(1,4-7,37)$} \\
\hline & $\begin{array}{l}\text { - Particles swell omni-directionally, pushing other components apart and resulting in matrix breakage. One of } \\
\text { the most common methods for promoting tablet disintegration is the addition of a disintegrant. How much a } \\
\text { disintegrant swells is directly related to its chemical structure and degree of crosslinking. }\end{array}$ & \\
\hline & $\begin{array}{l}\text { - Another factor that plays a role on the disintegrant performance is the compact porosity. On one hand, high porosity } \\
\text { with large empty spaces can diminish the force of disintegrant swelling on the surrounding matrix, decreasing its } \\
\text { efficiency. While on the other hand, low porosity and high compression force can hinder liquid penetration into the } \\
\text { matrix, resulting in a longer disintegration time. }\end{array}$ & \\
\hline & $\begin{array}{l}\text { - Substances that form gels when swelling are not effective disintegrants because the viscosity of the gel slows down } \\
\text { the liquid penetration and increases the disintegration time. Therefore, swelling gums, such as agar, karaya, and } \\
\text { tragacanth, are not very effective disintegrants. }\end{array}$ & \\
\hline \multirow[t]{3}{*}{$\begin{array}{l}\text { STRAIN } \\
\text { RECOVERY }\end{array}$} & $\begin{array}{l}\text { Described as the reversible viscoelastic process of deformation. During tableting, the disintegrant particles are } \\
\text { deformed. When in contact with water, the disintegrant tends to go back to its previous structure, recovering its } \\
\text { original shape. The disintegration medium can also favor the polymer chains of the disintegrant to adopt the most } \\
\text { energetically favorable position. }\end{array}$ & \multirow[t]{3}{*}{$(1,4-7,38)$} \\
\hline & $\begin{array}{l}\text { - The movements and volume expansion generated by the shape recovery process can cause the compact matrix to } \\
\text { break up. }\end{array}$ & \\
\hline & - $\quad$ This mechanism is less studied than swelling and wicking. & \\
\hline \multirow[t]{2}{*}{$\begin{array}{l}\text { INTERRUPTION } \\
\text { OF PARTICLE- } \\
\text { PARTICLE } \\
\text { BONDS }\end{array}$} & $\begin{array}{l}\text { During tablet manufacture, bonding can occur by solid bridges, mechanical interlocking, or intermolecular forces. } \\
\text { It is proposed that the interruption of these binding bonds is one of the disintegration mechanisms. An example } \\
\text { of that is microcrystalline cellulose. When the tablet is in contact with the disintegration medium it disintegrates } \\
\text { when the intermolecular forces between the cellulose fibers are disrupted by the imbedded water. }\end{array}$ & \multirow[t]{2}{*}{$(7,39,40)$} \\
\hline & $\begin{array}{l}\text { - Microcrystalline cellulose particles contribute to capillarity, i.e. liquid is drawn into the DF causing adhered particles } \\
\text { to be separated. }\end{array}$ & \\
\hline \multirow{3}{*}{$\begin{array}{l}\text { EXPANSION } \\
\text { DUE TO } \\
\text { HEATING } \\
\text { ENTRAPPED } \\
\text { AIR }\end{array}$} & There is a lot of controversy regarding this mechanism. & \multirow{3}{*}{$\begin{array}{l}(1,4-7,39, \\
41)\end{array}$} \\
\hline & $\begin{array}{l}\text { - Some authors report that exothermic interactions of materials with water generate heat, which can cause localized } \\
\text { stress, resulting in expansion of the air entrapped in the compact, thus resulting in disintegration of the matrix. }\end{array}$ & \\
\hline & $\begin{array}{l}\text { Other authors say that the heat generated by this process of wetting is too small to cause the entrapped air to } \\
\text { expand. If that was the case, then break-up of the compact would occur during manufacturing, when compacting } \\
\text { or ejecting the tablet. }\end{array}$ & \\
\hline \multirow{2}{*}{$\begin{array}{l}\text { RELEASE OF } \\
\text { GASEOUS } \\
\text { MATERIALS }\end{array}$} & $\begin{array}{l}\text { - Effervescent tablets are made in such a way that when in contact with water they release } \mathrm{CO}_{2} \text {, resulting in rapid } \\
\text { disintegration. }\end{array}$ & \multirow[t]{2}{*}{$(4,6)$} \\
\hline & - This is triggered by a reaction between an acid and carbonate or bicarbonate. & \\
\hline $\begin{array}{l}\text { ENZYMATIC } \\
\text { ACTION }\end{array}$ & - $\quad$ Enzymes which break down tablet components can be added to the product. & (6) \\
\hline
\end{tabular}

$D F$, dosage form.

disk, if used, is a soft mass having no palpably firm core" (9). Nevertheless, complete disintegration does not necessarily imply complete API dissolution (10).

Disintegration testing goes back as far as 1907 when it was first mentioned in the Swiss Pharmacopoeia describing the test in water (11). It was then incorporated in the British Pharmacopoeia (BP) in 1948 which described the test using test tubes (12). In the 1950's, the USP described the test using the basket-rack assembly apparatus, which is still used today to perform disintegration tests of DFs administered orally $(13,14)$. In addition to the disintegration test, a rupture test is used as a performance test of soft-shell capsules for dietary supplements, as directed in USP General Chapter <2040>, "Disintegration

Dissolution 
and Dissolution of Dietary Supplements", first published in USP 30-NF 25 in $2007(15,16)$.

The dimensions and measurements of the apparatus' components used for the disintegration test were changed quite a few times in the USP in order to harmonize with the European Pharmacopoeia and Japanese Pharmacopoeia (8). The apparatus consists of a basket-rack assembly, a low-form beaker $(1000 \mathrm{~mL})$, a thermostatic arrangement for heating the fluid, and a device for raising and lowering the basket in the immersion fluid at a constant defined frequency rate. The basket-rack assembly moves vertically along its axis with no appreciable horizontal motion or movement of the axis from the vertical (17).

There are two types of basket-rack assemblies, which are denominated as apparatus A and apparatus B. The European Pharmacopoeia, USP general chapter <701>, and Japanese Pharmacopoeia describe apparatus A while only the European Pharmacopoeia and Dietary Supplements chapter <2040> of the USP describe apparatus B $(17,16)$. According to USP chapter <2040>, apparatus $A$ should be used for tablets or capsules that are not greater than $18 \mathrm{~mm}$ long. For larger tablets or capsules, apparatus B should be used.

As mentioned above, disintegration testing is described in two chapters in the USP, general chapter $<701>$ and $<2040>$ for dietary supplements. There are some differences between the two chapters. For example, for hard gelatin capsules, chapter <701> uses water as the immersion medium, whereas chapter <2040> uses acetate buffer $\mathrm{pH}$ 4.5. For soft gelatin capsules, chapter $<701>$ recommends this DF to be tested like uncoated tablets while chapter $<2040\rangle$ uses a rupture test. In order to explore these differences and other parameters, Almukainzi et al. systematically investigated how the basket assembly (apparatus A and B) and other parameters impact the disintegration of different commercially available dietary supplement products (18). After this thorough study, many of the products tested had the disintegration time impacted by the different test conditions. This led to the conclusion that "the current harmonized $\mathrm{ICH}$ specifications for the disintegration test are insufficient to make the disintegration test into reliable test for dietary supplements" (18).

\section{APPARATUS SPECIFICATIONS AND PROCEDURES - USP <701> AND <2040>}

The 1-L low-form beaker should have 138 to $160 \mathrm{~mm}$ in height and an inside diameter of 97 to $115 \mathrm{~mm}$ for the immersion fluid. The immersion fluid temperature should be between $35^{\circ} \mathrm{C}$ and $39^{\circ} \mathrm{C}$, and the immersion frequency should be between 29 and 32 cycles per minute through a distance of not less than $53 \mathrm{~mm}$ and not more than 57 $\mathrm{mm}$. The volume of the fluid in the vessel is such that at the highest point of the upward stroke of the wire mesh remains at least $15 \mathrm{~mm}$ below the surface of the fluid and descends to not less than $25 \mathrm{~mm}$ from the bottom of the vessel on the downward stroke. At no time should the top of the basket-rack assembly become submerged. The time required for the upward stroke is equal to the time required for the downward stroke, and the change in stroke direction is a smooth transition, rather than an abrupt reversal of motion. The specifications for each apparatus regarding the basket-rack assembly and disks are summarized in Table 2 and illustrated in Figure 2 (16, 17).

Table 2. USP Specifications for Basket-Rack Assembly and Disk for Apparatus $A$ and $B$

\begin{tabular}{|c|c|c|}
\hline & Apparatus A & Apparatus B \\
\hline \multicolumn{3}{|l|}{ Basket-rack assembly } \\
\hline Tubes (n) & 6 & 3 \\
\hline Tube length $($ mean $\pm S D)(\mathrm{mm})$ & $77.5 \pm 2.5$ & $77.5 \pm 2.5$ \\
\hline Inside diameter range (mm) & $20.7-23$ & $32.0-34.6$ \\
\hline Wall thickness range $(\mathrm{mm})$ & $1.0-2.8$ & $2.0-3.0$ \\
\hline Plates (n) & 2 & 2 \\
\hline Plate diameter range $(\mathrm{mm})$ & $88-92$ & $95-99$ \\
\hline Plate thickness range $(\mathrm{mm})$ & $5-8.5$ & $7.5-10.5$ \\
\hline Plate holes (n) & 6 & 3 \\
\hline Hole diameter range $(\mathrm{mm})$ & $22-26$ & $33-34$ \\
\hline Wire weave gap range $(\mathrm{mm})$ & $1.8-2.2$ & - \\
\hline Wire diameter range & $0.57-0.66 \mathrm{~mm}$ & $0.025 \mathrm{in.}$ \\
\hline \multicolumn{3}{|l|}{ Disks } \\
\hline Thickness (mean \pm SD) $(\mathrm{mm})$ & $9.5 \pm 0.15$ & $15.3 \pm 0.15$ \\
\hline Diameter (mean $\pm \mathrm{SD})(\mathrm{mm})$ & $20.7 \pm 0.15$ & $31.4 \pm 0.13$ \\
\hline Specific gravity range & $1.18-1.20$ & $1.18-1.20$ \\
\hline Holes (n) & 5 & 7 \\
\hline Hole diameter (mean $\pm S D$ ) & $2 \pm 0.1$ & $3.15 \pm 0.1$ \\
\hline
\end{tabular}

The disintegration test might be performed differently for each DF as specified in USP chapter $<701>$ (17). For example, when testing uncoated tablets in apparatus $A$, one dosage unit should be placed in each of the six tubes of the basket and, if prescribed, add a disk. The immersion fluid can be water or other specified medium, with temperature maintained at $37 \pm 2{ }^{\circ} \mathrm{C}$. Each monograph specifies the time the test should 


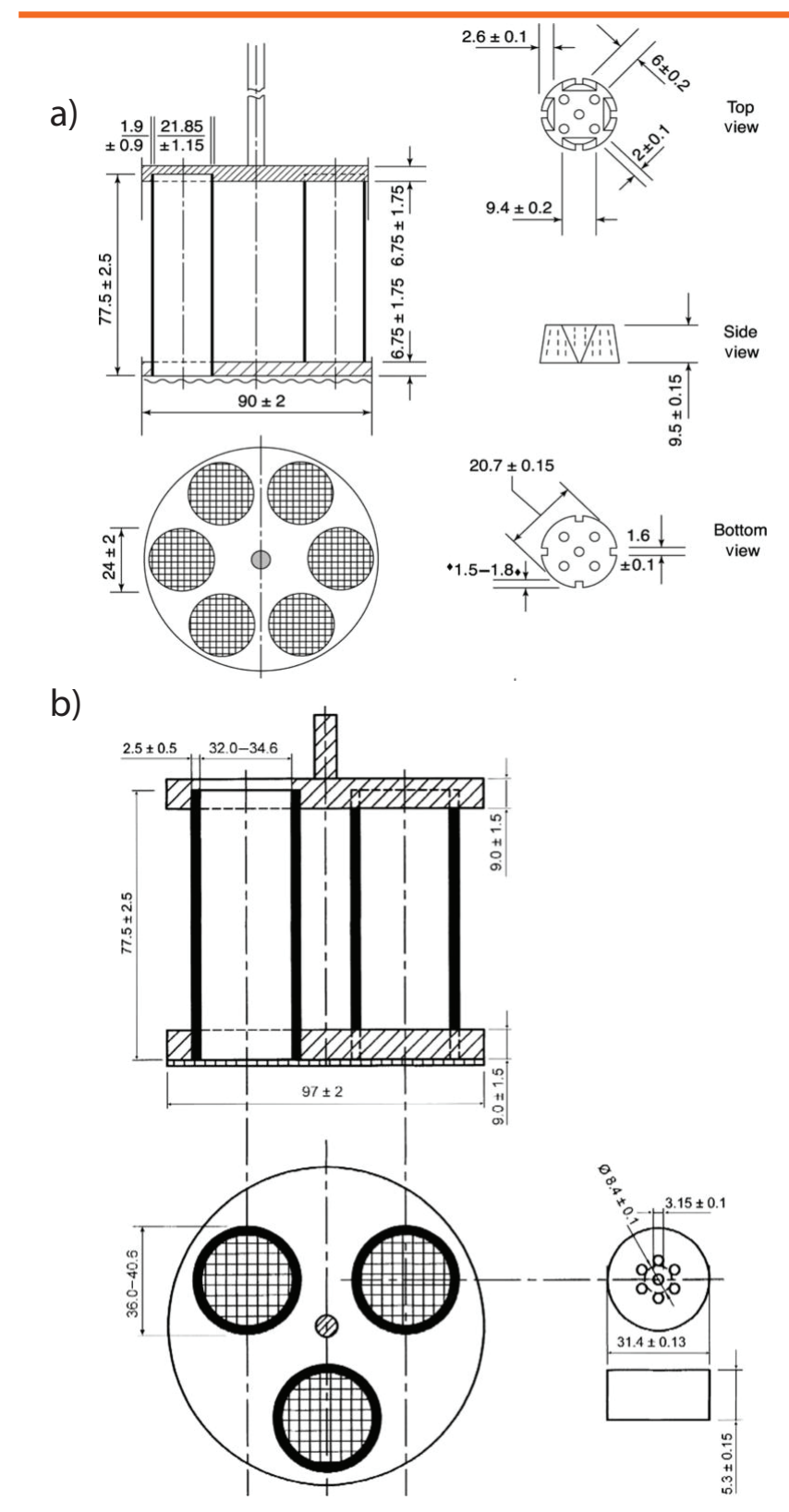

Figure 2. USP specifications for disintegration apparatus $A$ (a) and apparatus B (b). Reprinted with permission. (02017 The United States Pharmacopeial Convention.

run for and that all tablets should have disintegrated completely at the end of the time limit. Interestingly, the disintegration test for uncoated tablets in general chapter USP <2040> specifies a 30-min time limit, showing that the specifications in $<701>$ and $<2040>$ are not identical (16). The specifications are described in each chapter for other DF's, such as plain coated tablets, delayed release tablets, buccal tablets, sublingual tablets, hard- and softgelatin capsules; details are listed in Table 3 . There are not only differences between the two USP chapters as to how to conduct disintegration for the different DF, but there are also differences between the pharmacopeias of the different regions. These differences were summarized by
Al-Gousous and Langguth (10). The problem with these differences in the disintegration testing conditions is that it can lead to different test results. A study using entericcoated soft gelatin capsules showed that the conditions specified by the USP and European Pharmacopoeia led to different test results (19).

Generally, when 1 or 2 tablets fail to disintegrate completely, the test should be repeated on 12 additional tablets. The requirement is met if at least 16 of the total of 18 tablets tested are disintegrated (17).

\section{DISINTEGRATION AS A QUALITY CONTROL TEST}

According to decision Tree \#7 in the International Council for Harmonization (ICH) Tripartite Guideline Q6A, the use of disintegration testing instead of dissolution is allowed when the following criteria are met $(1,20)$ :

1. Immediate-release dosage form (i.e. no modified release);

2. The drug product contains a drug that is highly soluble throughout the physiological range (dose/solubility volume $<250 \mathrm{~mL}$ from $\mathrm{pH} 1.2$ to 6.8 );

3. Rapidly dissolving products (dissolution $>80 \%$ in 15 minutes at $\mathrm{pH} 1.2,4.0$, and 6.8); and

4. Establishment of a relationship between disintegration and dissolution or when disintegration is shown to be more discriminating than dissolution.

The US Food and Drug Administration (FDA) draft guideline on dissolution testing also allows replacement of dissolution by disintegration testing for BCS class I and III drug products using the same criterion of rapid dissolution specification ( $Q=80 \%$ in 15 minutes). When this criterion is met, the product should completely disintegrate within 5 min in $0.01 \mathrm{M} \mathrm{HCl}$ (via USP apparatus) (21).

USP chapter <2>, Oral drug products - Product quality test, states that disintegration testing is used only as a quality control test and not as a product performance test following the $\mathrm{ICH}$ guidance criteria for tablets (22). Furthermore, it states that "only when disintegration has been correlated with dissolution of a dosage form can a disintegration test be used as a product performance test", also following the ICH guidance criteria.

Since disintegration tests are less complicated and less time consuming than dissolution tests, its use is desirable in a quality-by-design (QbD) approach. Due to its simplicity, concentrating more efforts and research on disintegration 
Table 3. Disintegration Test Specified for Each Dosage Form According to USP Chapters <701> and <2040>

\begin{tabular}{|c|c|c|}
\hline Dosage Form & USP General Chapter <701> & USP Dietary Supplements Chapter <2040> \\
\hline Uncoated Tablets & $\begin{array}{l}\text { Immersion fluid: water or the specified medium; if } \\
\text { prescribed, add a disk. Use the time specified in the } \\
\text { individual monograph. }\end{array}$ & $\begin{array}{l}\text { Immersion fluid: water or the specified medium for } 30 \\
\text { min. If prescribed, add a disk. }\end{array}$ \\
\hline Plain Coated Tablets & $\begin{array}{l}\text { Same as uncoated tablets using the time specified in } \\
\text { the individual monograph. }\end{array}$ & $\begin{array}{l}\text { Immersion fluid: water or the specified medium for } 30 \\
\text { min. If prescribed, add a disk. For tablets with external } \\
\text { sugar coating: immerse in water at room temperature for } \\
5 \text { min. }\end{array}$ \\
\hline $\begin{array}{l}\text { Delayed-Release (enteric coated) } \\
\text { Tablets }\end{array}$ & $\begin{array}{l}\text { Immersion fluid: Start with simulated gastric fluid. } \\
\text { After } 1 \mathrm{~h} \text {, no evidence of disintegration, cracking, or } \\
\text { softening. Continue using simulated intestinal fluid for } \\
\text { the time specified in the monograph. } \\
\text { For tablets with external sugar coating: immerse in } \\
\text { water at room temperature for } 5 \text { min. }\end{array}$ & $\begin{array}{l}\text { Omit the use of a disk. } \\
\text { Immersion fluid: Start with simulated gastric fluid. After } \\
1 \mathrm{~h} \text {, no evidence of disintegration, cracking, or softening. } \\
\text { Continue using simulated intestinal fluid for the time } \\
\text { specified in the monograph. } \\
\text { For tablets with external sugar coating: immerse in water } \\
\text { at room temperature for } 5 \text { min. }\end{array}$ \\
\hline $\begin{array}{l}\text { Delayed-Release (enteric coated) } \\
\text { Soft Shell Capsules }\end{array}$ & - & $\begin{array}{l}\text { Immersion fluid: Start with simulated gastric fluid, omit } \\
\text { the use of disks. After } 1 \mathrm{~h} \text {, no evidence of disintegration } \\
\text { or rupture. Continue using simulated intestinal fluid with } \\
\text { disks for no more than } 60 \text { min. }\end{array}$ \\
\hline Hard Shell Capsules & $\begin{array}{l}\text { Same as uncoated tablets using the time specified in } \\
\text { the individual monograph. } \\
\text { Attach a removable wire cloth to the surface of the } \\
\text { upper plate of the basket-rack assembly. }\end{array}$ & $\begin{array}{l}\text { Same as uncoated tablets for } 30 \text { min. } \\
\text { Immersion fluid: } \mathrm{pH} 4.5 \text { acetate buffer. } \\
\text { Attach a removable wire cloth to the surface of the upper } \\
\text { plate of the basket-rack assembly. }\end{array}$ \\
\hline Soft Shell Capsules & Same as hard gelatin capsules & $\begin{array}{l}\text { Rupture test for soft shell capsules: performed in } \\
\text { dissolution Apparatus } 2 \text { (paddle) operated at } 50 \mathrm{rpm} \text { with } \\
500 \mathrm{~mL} \text { of water as the immersion medium for } 15 \mathrm{~min} \text {. }\end{array}$ \\
\hline Buccal Tablets & Same as uncoated tablets for $4 \mathrm{~h}$ & - \\
\hline Sublingual Tablets & $\begin{array}{l}\text { Same as uncoated tablets using the time specified in } \\
\text { the individual monograph. }\end{array}$ & - \\
\hline
\end{tabular}

-, Not specified

testing could result in time and resource saving for quality control (QC) departments in pharmaceutical industries throughout the product's lifecycle (10). Nevertheless, when using disintegration as a quality control test, it must be reproducible within the set specifications (8).

\section{DISINTEGRATION IN THE REAL WORLD}

\section{Early stage development}

Commonly, at early stages of drug development, there are restricted or no pharmacokinetic data from the IR formulation under development. Not much data exist about the solubility in different media (23). For that reason, dissolution testing for quality control is unfeasible at this stage. Scientists from Pfizer name this first stage in the development process as the "exploratory development" stage (24). The focus of this stage is to reach 'proof-of-concept' to decide "as to whether the candidate is suitable for further development" (24).

As stated by Klute, at this point in early drug development, the "API characteristics such as particle size and disintegration are monitored to ensure batch quality for
Pfizer immediate release (IR) solid oral dosage forms, therefore dissolution is no longer the default method of choice to ensure product performance" (24).

As shown in Figure 1, in order to have the API in solution for absorption, the tablet has to first disintegrate into primary particles, and then API particles can dissolve. Thus, the critical quality attributes for drug solubilization are the tablet disintegration rate and API dissolution rate. For Pfizer, if rapid disintegrating tablet formulation is used and the API particle size is small enough to completely dissolve, the disintegration test is a suitable surrogate for tablet performance and is adequate for early stage development (24). QC dissolution testing at this stage is negated. Instead, the key $Q C$ test to certify tablet performance is disintegration testing, which is included "as the key performance test on the drug product specification as part of clinical applications submitted in support of early clinical studies using IR tablets" (24).

In the cases where the 'proof-of-concept' is positive, the drug candidate will undergo further development, where 
a QC dissolution test is more appropriate and is used as a tool to predict the formulation bioperformance (24).

\section{Relationship between disintegration and dissolution} Drugs that have high solubility (BCS classes I and III) and high dissolution number dissolve within the gastrointestinal tract and may not have dissolution as the rate limiting step, as long as the DF disintegrates and releases the API particles (8). For BCS class I and III, it is expected that the drug's highest dose dissolves within the physiological $\mathrm{pH}$; BCS class II and IV drugs might not dissolve within the small intestinal passage. Here, formulation approaches are often used to increase API dissolution. In all cases, dissolution will happen after disintegration, i.e., after liberation of the API from the DF $(8,10)$. Hence, when facing the scenario where the API dissolution is not dependent on the formulation but is dependent on the drug particle properties, particle size or surface area disintegration might be the appropriate parameter to predict API dissolution (25).

The experiment set up, such as media composition and $\mathrm{pH}$, may also play a role in the disintegration test result. Stamatakis et al. investigated the influence of the medium $\mathrm{pH}$ on the disintegration time of commercially available phosphate binder formulations (26). Tablet formulations of calcium carbonate, calcium acetate, and aluminum hydroxide, and capsule formulations of aluminum hydroxide were analyzed using three different media: simulated gastric fluid $(\mathrm{pH} 1.5)$, distilled water (pH 5.1), and simulated intestinal fluid ( $\mathrm{pH}$ 7.5). The USP standard disintegration apparatus at the time (USP 23-NF 18) was used. Their results showed that nine out of the 15 products tested were sensitive to changes in $\mathrm{pH}$, showing differences in disintegration time. They concluded that "the $\mathrm{pH}$ significantly affected in vitro disintegration in the majority of phosphate binders tested". This study, thus, portrays how the disintegration time can vary depending on the immersion medium $\mathrm{pH}$.

In a study done in 1971 by Alam and Parrott, the disintegration time of hydrochlorothiazide tablets (granulated with acacia, polyvinylpyrrolidone, or starch as binding agents) was measured in four different media: distilled water, $0.1 \mathrm{~N} \mathrm{HCl}$, simulated intestinal fluid, and borate buffer at $\mathrm{pH} 10$ (27). The average disintegration time for the tablets granulated with all three binders was faster than the USP disintegration time, according to the available USP at the time. Besides that, each formulation had significant differences on the disintegration time throughout the media tested.
Furthermore, Zuo et al. demonstrated how the media composition can affect the disintegration time (28). In their study, they used different beverages (alcoholic beverages, regular cola (Pepsi), and orange juice (Minute Maid)) as media and compared it to the pharmacopeial immersion medium water, which is the USP reference medium in $<701>$ and for dietary supplements formulated as tablets $(16,17)$. Four commercial tablet products, calcium citrate, Ester-C, Boswellia serrata extract, and cinnamon extract were analyzed in the cited media. Orange juice and high alcohol content in particular extended the disintegration times. For orange juice, the extension was attributed to the increased viscosity of the orange juice but could also be an effect of the low pH. For high alcoholic beverages the hydration of disintegrants could be impacted, which in turn impacts DF disintegration. The study concluded that "with the exception of $5 \%$ alcohol, all beverages had a significant effect on the disintegration time of calcium citrate and Ester-C. Only cola, orange juice, and $40 \%$ alcohol significantly influenced the disintegration time of the cinnamon extract. Therefore, the tested beverages should not be used to replace water when ingesting therapeutic products" (28). Taking these results into consideration, experimental conditions must be carefully chosen because they impact the test results $(18,28,29)$.

Regarding the rupture test as a performance test for softshell capsules established in USP 30-NF 25 (2007) under the General Chapter $\langle 2040\rangle$, Bachour et al. evaluated the use of this test as a quality control tool for long-term stability samples using different enzymes $(16,30)$. The rupture test for soft-shell capsules can fail for samples that were exposed to stability conditions, an aging problem that has already been reported by the nutraceutical industry. This may be due to gelatin cross-linking, as stated in the USP General Chapter $<711>$, which states "Gelatin, in the presence of certain compounds and/or in certain storage conditions, including but not restricted to high humidity and temperature, may present cross-linking. A pellicle may form on the external and/or internal surface of the gelatin capsule shell or on the dosage form that prevents the drug from being released during dissolution testing" (31). With this in view, Bachour performed a rupture test and compared oil-based, oral multivitamin soft-shell capsules with stability samples of the same product. The immersion medium was water and enzyme-containing media (pepsin, pancreatin, papain, and bromelain) as used for rupture and dissolution testing of gelatin-based capsules. The stability sample capsules failed to pass the requirements in all tested media, while the commercial capsules passed. Nevertheless, the study also reports that 
"the cross-linked capsules ruptured readily when emptied out of the vessel, thus the capsules would likely rupture in the stomach, [...] even if cross-linked" (30). This indicates that the observed "fail to rupture" might not represent the in-vivo conditions where the capsule is exposed to motility forces. Therefore, in vitro, the rupture test can detect gelatin cross-linking in long-term stability samples but new or modified test methods are needed to assess the performance of aged soft-shell gelatin capsules when using the rupture test.

The requirements of ICH/FDA and USP to substitute dissolution testing with disintegration testing require the establishment of a relationship between disintegration and dissolution. This may not be an easy task to accomplish, given that the dissolution rate of IR solid formulations is not necessarily determined by disintegration, as shown by Radwan et al. (32).

Nevertheless, Nickerson et al. were able to obtain a relationship between disintegration and dissolution for a rapidly dissolving immediate-release tablet with a highly soluble drug (BCS class I), thus justifying the use of disintegration in lieu of dissolution testing (33). In their work, given the stated characteristics, drug release from the DF was shown to be limited by disintegration. The authors reported a linear relationship between disintegration and dissolution results for that particular drug product, concluding that disintegration would be an appropriate drug product quality control method to evaluate drug release from that DF.

Gupta et al., however, compared 12 different IR tablet formulations of Verapamil hydrochloride and no direct relationship was obtained between the disintegration and dissolution across all formulations (34). This was attributed to the interactions between different formulation components, which showed that the dissolution process depends not only on the disintegrating agent but also on formulation components. In this study, only one out of the 12 formulations met the ICH Q6A criteria, therefore being the only formulation suitable to use for the disintegration test instead of dissolution as the QC test (34). Thus, it becomes clear that the determination of a relationship between disintegration and dissolution test is not an easy task, and a systematic study is needed before using disintegration testing as part of the drug product specifications.

Uebbing et al. went further and demonstrated that if disintegration occurs first, and if dissolution is controlled by the drug particle properties based on API characteristics and not on formulation factors, then disintegration can be used as a performance test for rapidly disintegrating tablets beyond the current FDA criteria (25). Their mechanistic study differentiated between API controlled dissolution behavior and DF impacted/controlled dissolution. They concluded that if the formulation interferes with dissolution, then the dissolution test should be used as the QC test. Similar to this study, Han and Gallery described the use of disintegration instead of dissolution testing for liquid-filled gelatin capsules (35). Although it was an encapsulated poorly soluble drug, they argued that if the product was to be administered in a spoon instead of a capsule, no dissolution test would be required. This case study also shows how a disintegration test can be used beyond $\mathrm{ICH}$ criteria as a surrogate for dissolution testing.

\section{CONCLUSION}

Further work is still needed to establish the scientific framework for using disintegration testing as a performance test for different DFs. Disintegration is an important quality control test today. In the future, disintegration testing could become a release test for formulations with API-controlled dissolution. Hence, in cases like this, disintegration is the critical quality attribute of the DF and determines the onset of dissolution, and dissolution is only determined by API properties.

With a proper understanding and demonstration or justification of the mechanistic details of drug dissolution from the DF, dissolution testing might be replaced by disintegration testing for certain DFs as a performance test. Disintegration testing can save time and cost for QC departments in the pharmaceutical industry due to its simplicity.

In order to harmonize the disintegration test throughout the different pharmacopeias, many specification changes have been made in the USP. These changes still need to be thoroughly investigated as to how much - especially the current beaker specifications - they might impact the disintegration time of dosage forms. To make this matter more clear, more research is needed to make disintegration test results less variable. This will improve the mechanistic understanding of the disintegration process and might lead to an in vivo predictive disintegration test.

\section{ACKNOWLEDGMENTS}

The authors thank the Drug Development and Innovation Centre of the University of Alberta. 


\section{CONFLICT OF INTEREST}

Gregory K Webster is an employee of AbbVie. The other authors declare no conflicts of interest related to this work.

\section{REFERENCES}

1. Markl, D.; Zeitler, J. A. A review of disintegration mechanisms and measurement techniques. Pharm. Res.; 2017, 34, 890-917. DOI: 10.1007/s11095-017-2129-z.

2. Rubinstein, M. H.; Bodey, D. M. Disaggregation of compressed tablets. J Pharm Sci. 1976, 65, 1749-1753. DOI: 10.1002/ jps.2600651214.

3. Aulton, M. E.; Taylor, K.; Eds. Aulton's Pharmaceutics. The Design and Manufacture of Medicines. $4^{\text {th }}$ ed. Churchill Livingstone Elsevier, 2013.

4. Quodbach, J.; Kleinebudde, P. A critical review on tablet disintegration. Pharm. Dev. Technol. 2016, 21, 763-774. DOI: 10.3109/10837450.2015.1045618.

5. Lowenthal, W. Disintegration of tablets. J. Pharm. Sci. 1972, 61, 1695-1711. DOI: 10.1002/jps.2600611102.

6. An overview of disintegrants. https://www.lfatabletpresses. com/articles/overview-of-disintegrants. Accessed Feb 22, 2018.

7. Desai, P. M.; Liew, C. V.; Heng, P. W. S. Review of disintegrants and the disintegration phenomena. J. Pharm. Sci. 2016, 105, 2545-2555. DOI: 10.1016/j.xphs.2015.12.019.

8. Donauer, N.; Löbenberg, R. A mini review of scientific and pharmacopeial requirements for the disintegration test. Int. J. Pharm. 2007, 345, 2-8. DOI: 10.1016/j.ijpharm.2007.08.045.

9. The United States Pharmacopeia and National Formulary USP 40-NF 35; The United States Pharmacopeial Convention, Inc.: Rockville, MD, 2017.

10. Al-Gousous, J.; Langguth, P. Oral solid dosage form disintegration testing - the forgotten test. J. Pharm. Sci. 2015, 104, 2664-2675. DOI: 10.1002/jps.24303.

11. Pharmacopoeia Helvetica. The Swiss Pharmacopoeia Commission: Bern, Switzerland, 1907.

12. British Pharmacopoeia. The General Council of Medical Education and Registration of the United Kingdom: London, 1948.

13. The United States Pharmacopeia. The United States Pharmacopeial Convention, Inc.: Rockville, MD, 1950.

14. Gershberg, S.; Stoll, F. D. Apparatus, for tablet disintegration, and for shaking-out extractions. J. Am. Pharm. Assoc. (Scientific ed). 1946, 35, 284-287. DOI: 10.1002/jps.3030350910.

15. Almukainzi, M.; Salehi, M.; Chacra, N. A. B.; Löbenberg, R. Comparison of the rupture and disintegration tests for soft-shell capsules. Dissolution Technol. 2011, 18, 21-25. DOI: 10.14227/ DT180111P21.

16. <2040> Disintegration and Dissolution of Dietary Supplements. In The United States Pharmacopeia and National Formulary USP 40-NF 35; The United States Pharmacopeial Convention, Inc.: Rockville, MD, 2017.
17. <701> Disintegration. In The United States Pharmacopeia and National Formulary USP 40-NF 35; The United States Pharmacopeial Convention, Inc.: Rockville, MD, 2017.

18. Almukainzi, M.; Salehi, M.; Araci Bou-Chacra, N.; Löbenberg, R. Investigation of the performance of the disintegration test for dietary supplements. AAPS J. 2010, 12, 602-607. DOI: 10.1208/ s12248-010-9221-1.

19. Al-Gousous, J.; Langguth, P. European versus United States Pharmacopeia disintegration testing methods for enteric-coated soft gelatin capsules. Dissolution Technol. 2015, 22, 6-8. DOI: 10.14227/DT220315P6.

20. International Conference on Harmonisation. 1999. ICH Q6A Guideline: Specifications: Test procedures and acceptance criteria for new drug substances and new drug products: Chemical substances. Q6A. https://www.ich.org/fileadmin/ Public_Web_Site/ICH_Products/Guidelines/Quality/Q6A/ Step4/Q6Astep4.pdf. Published 6 Oct 1999. Accessed 16 Apr 2018.

21. Dissolution Testing and Specification Criteria for ImmediateRelease Solid Oral Dosage Forms Containing Biopharmaceutics Classification System Class 1 and 3 Drugs: Guidance for Industry; U.S. Department of Health and Human Services, Food and Drug Administration, Center for Drug Evaluation and Research (CDER), U.S. Government Printing Office: Washington, DC, 2015.

22. $<2>$ Oral Drug Products-Product Quality Tests. In The United States Pharmacopeia and National Formulary USP 40 -NF 35; The United States Pharmacopeial Convention, Inc.: Rockville, MD, 2017.

23. Bou-Chacra, N.; Melo, K. J. C.; Morales, I. A. C.; Stippler, E. S.; Kesisoglou, F.; Yazdanian, M.; Löbenberg, R. Evolution of choice of solubility and dissolution media after two decades of biopharmaceutical classification system. AAPS J. 2017, 19, 9891001. DOI: $10.1208 / \mathrm{s} 12248-017-0085-5$.

24. Klute, A. S. Disintegration testing: release dosage forms in exploratory development. Am. Pharm. Rev. 2009, 12, 90-93.

25. Uebbing, L.; Klumpp, L.; Webster, G. K.; Löbenberg, R. Justification of disintegration testing beyond current FDA criteria using in vitro and in silico models. Drug. Des. Devel. Ther. 2017, 11, 1163-1174. DOI: 10.2147/DDDT.S131213.

26. Stamatakis, M. K.; Alderman, J. M.; Meyer-Stout, P. J. Influence of $\mathrm{pH}$ on in vitro disintegration of phosphate binders. Am. J. Kidney Dis. 1998, 32, 808-812. DOI: 10.1016/S0272-6386(98)70137-4.

27. Alam, A. S.; Parrott, E. L. Effect of dissolution media on disintegration and dissolution of hydrochlorothiazide tablets. $J$ Pharm. Sci. 1971, 60, 795-797. DOI: 10.1002/jps.2600600531.

28. Zuo, J.; Gao, Y.; Almukainzi, M.; Löbenberg, R. Investigation of the disintegration behavior of dietary supplements in different beverages. Dissolution Technol. 2013, 20, 6-9. DOI: 10.14227/ DT200413P6.

29. Schmid, K.; Löbenberg, R. Influence of the changed USP specifications on disintegration test performance. Dissolution Technol. 2010, 17, 6-10. DOI: 10.14227/DT170110P6. 
30. Bachour, G.; Bou-Chacra, N. A.; Löbenberg, R. Evaluation of the rupture test for stability studies of soft-shell capsules. Dissolution Technol. 2017, 24, 16-19. DOI: 10.14227/DT240217P16.

31. <711> Dissolution. In The United States Pharmacopeia and National Formulary USP 39-NF 34 ; The United States Pharmacopeial Convention, Inc: Rockville, MD, 2016.

32. Radwan, A.; Wagner, M.; Amidon, G. L.; Langguth, P. Biopredictive tablet disintegration: effect of water diffusivity, fluid flow, food composition and test conditions. Eur. J. Pharm. Sci. 2014, 57, 273-279. DOI: 10.1016/j.ejps.2013.08.038.

33. Nickerson, B.; Kong, A.; Gerst, P.; Kao, S. Correlation of dissolution and disintegration results for an immediate-release tablet. J. Pharm. Biomed. Anal. 2018, 150, 333-340. DOI: 10.1016/j. jpba.2017.12.017.

34. Gupta, A.; Hunt, R. L.; Shah, R. B.; Sayeed, V. A.; Khan, M. A. Disintegration of highly soluble immediate release tablets: a surrogate for dissolution. AAPS PharmSci Tech. 2009, 10, 495499. DOI: 10.1208/s12249-009-9227-0.

35. Han, J. H.; Gallery, J. A risk-based approach to in vitro performance testing: A case study on the use of dissolution vs. disintegration for liquid-filled gelatin capsules. Am. Pharm. Rev. 2006, 9, 152-157.

36. Kissa, E. Wetting and wicking. Text Res. J. 1996, 66, 660-668. DOI: 10.1177/004051759606601008.

37. Patel, N.; Hopponent, R. Mechanism of action of starch as a disintegrating agent in aspirin tablets. J. Pharm. Sci. 1966, 55, 1065-1068. DOI: 10.1002/jps.2600551015.

38. Patel, S.; Kaushal, A.; Bansal, A. Effect of particle size and compression force on compaction behavior and derived mathematical parameters of compressibility. Pharm. Res. 2007, 24, 111-124. DOI: 10.1007/s11095-006-9129-8.

39. Lowenthal, W. Mechanism of action of tablet disintegrants. Pharm. Acta Helv. 1973, 48, 589-609.

40. Ferrari, F.; Bertoni, M.; Bonferoni, M.; Rossi, S.; Caramella, C.; Nyström, C. Investigation on bonding and disintegration properties of pharmaceutical materials. Int. J. Pharm. 1996, 136, 71-79. DOI: 10.1016/0378-5173(96)04489-4.

41. Matsumaru, H. Studies on the mechanism of tablet compression and disintegration IV. Yakugaku Zasshi. 1959, 79, 63-64. DOI: 10.1248/yakushi1947.79.1_63. 